\title{
Neolithic transition in Europe: the radiocarbon record revisited
}

\author{
Marina Gkiasta ${ }^{1}$, Thembi Russell ${ }^{2}$, Stephen Shennan ${ }^{1} \dagger$ and James Steele ${ }^{2}$
}

Understanding the introduction of farming and the adoption of Neolithic culture continues to be a major research objective in Europe. The authors make use of a new database of radiocarbon dates from Mesolithic and Neolithic sites to map the transition. While the overall effect is still a diffusion into Europe from the south-east, detailed spatial analysis reveals fascinating local variations: in some places change was rapid, and one population replaced another, in others it was gradual and owed to incoming ideas rather than people.

Keywords: Origns of agriculture; Neolithic; genetics; Europe

\section{Introduction}

There is a long tradition of using radiocarbon dates to map the spread of farming and the arrival of Neolithic cultures across Europe. Clark (1965) was the first to do this, plotting only the earliest settlements in each territory; he noted "the need, in view of the element of uncertainty inherent in individual determinations, to dispose of samples numerous enough to yield convincing patterns" (1965:66). He was able to discern a pattern of spread into Europe along the Danube from an origin in the South East, with a long delay before farming reached the North European Plain, south Scandinavia, and other places in western Europe from the Alps to northern Britain and Ireland (ibid::67).

Ammerman and Cavalli-Sforza (1971) used regression methods to describe the average rate at which farming spread. They also used the correlation coefficient $(r)$ to assess the extent to which regional rates of spread differed from that overall average. They reported an average diffusion rate from an assumed origin in Jericho of about $1 \mathrm{~km} /$ year, and found a high value for $r(0.89)$ in their sample of 53 Neolithic sites - suggesting that this rate was quite representative of the process generally. However, they also noted evidence for regional variation in rates (from $0.7 \mathrm{~km} /$ year in the Balkans, to $5.6 \mathrm{~km} /$ year for the Bandkeramik culture). Subsequently, they used spatial interpolation methods to generate isochron maps that plotted the mean rates of spread of farming (and of the disappearance of hunting and gathering) in two dimensions (Ammerman \& Cavalli-Sforza 1984). They conjectured that the pattern observed may have been produced, not by cultural diffusion (the adoption of cultural traits), but by a gradual process of spatial population expansion and replacement. They found support for this 'demic diffusion' model in a synthetic gene map, generated

\footnotetext{
${ }^{1}$ Institute of Archaeology, 31-34 Gordon Square, London WC1H OPY, England.

${ }^{2}$ Department of Archaeology, University of Southampton, Highfield, Southampton SO17 1BJ, England. †(s.shennan@ucl.ac.uk)
}

Received 9 January 2003; Accepted 9 January 2003; Revised 9 January 2003. 
from the SE-NW gradient in the first Principal Component of variation in allele frequencies of modern Europeans. In their monograph, they reported that such a cline (trend) in gene frequencies was expected where farming had spread by demic diffusion. The steepness of the cline was modelled as a function of the rate of reproductive mixing with hunter-gatherers; when this rate was very low, the cline would be relatively flat, such that gene pools near the origin of the diffusion would contain about $90 \%$ of initial farmers' genes, and gene pools at the periphery would contain $75 \%$ of them.

Subsequent work has transformed this simple picture. It has been shown mathematically that identical travelling waves for the spread of farming can be generated by demic expansion, demic diffusion, or by trait adoption-diffusion (Aoki, Shida \& Shigesada 1996). Archaeologists have pointed to the very different rates of the spread of farming in different regions of Europe, and have challenged the use of synthetic gene maps to validate the demic diffusion model (since such maps contain no information about the chronology of dispersals). The methodology of generating synthetic gene maps has also been challenged, since it can potentially produce clines even in spatially random data (Sokal, Oden \& Thomson 1999). Furthermore, it is now recognized that genuine clines in gene frequencies can be produced by population replacement with successive founder effects (cf. Barbujani et al. 1995), or by demic diffusion with acculturation (cf. Rendine et al. 1996), or by gradients in duration of natural selection when the selection pressures are initiated by adoption of a new economic strategy, rather than by population replacement (Fix 1996, 1997).

Some recent genetic studies have found distinctive European mtDNA matrilineages that have an apparently Upper Palaeolithic or Mesolithic common ancestor; it has been estimated by Richards et al. $(1996,1998,2000)$ that female immigrant farmers contributed only about $20 \%$ of the modern European mitochondrial gene pool. A similar conclusion has been reached with respect to male genetic contributions as measured from Y-chromosome markers (Semino et al. 2000). Thus, much recent genetic work indicates that, at the continental scale, farming spread into Europe by a mixture of demic expansion, demic diffusion, and trait adoptiondiffusion, with adoption-diffusion as the predominant mechanism. However, other studies suggest that both female and male immigrant farmers may have contributed more significantly to the modern European gene pool ( $-45 \%$ of modern Y-chromosomal variation, Rosser $e t$ al. 2000; see also for mtDNA: Simoni et al. 2000, and for nuclear genes and classic protein markers: Barbujani and Bertorelle 2001). Moreover, Chikhi et al. (2002) have shown that it is not straightforward to make inferences from percentages of genes in modern populations to relative proportions of bearers of genes in the remote past. The link between the two has to be modelled mathematically. Chikhi et al.'s results suggest that when this is done demic diffusion provides the best explanation of present-day patterns. Bentley et al. (2003) synthesise Chikhi's approach with new archaeological evidence for sex-biased dispersal.

Meanwhile, new archaeological models of the transition from foraging to farming have been proposed which allow a more sensitive interpretation of the radiocarbon data. Bogucki (e.g Bogucki \& Grigiel 1993) has proposed a two stage (pioneer/established) model of demic diffusion in North Central Europe. Zvelebil and collaborators (1991, 1996, 2000) have proposed a three-phase model of the transition (availability, substitution, and consolidation) in which the local and regional rate of spread becomes a measure of the absolute duration of these successive transitional phases. It is now widely recognized that there may have been significant regional 
variation in the relative importance of demic expansion, demic diffusion, and of trait adoptiondiffusion as the mechanisms of spread (see e.g. Arias 1999, Gronenborn 1999). At the same time disagreements continue over the nature of the processes responsible for some of the most important Early Neolithic phenomena, especially the spread of the Central European Linearbandkeramik and the Mediterranean Impressed Ware. One recent diagram of the regional variation in mechanisms of spread is reproduced in Figure 1 (from Zvelebil \& Lillie 2000).

It is clear that the time is ripe for a re-evaluation both of the radiocarbon record, and of its potential as a test-bed for alternative models of the demography of the Neolithic transition. In this paper we report our preliminary findings.

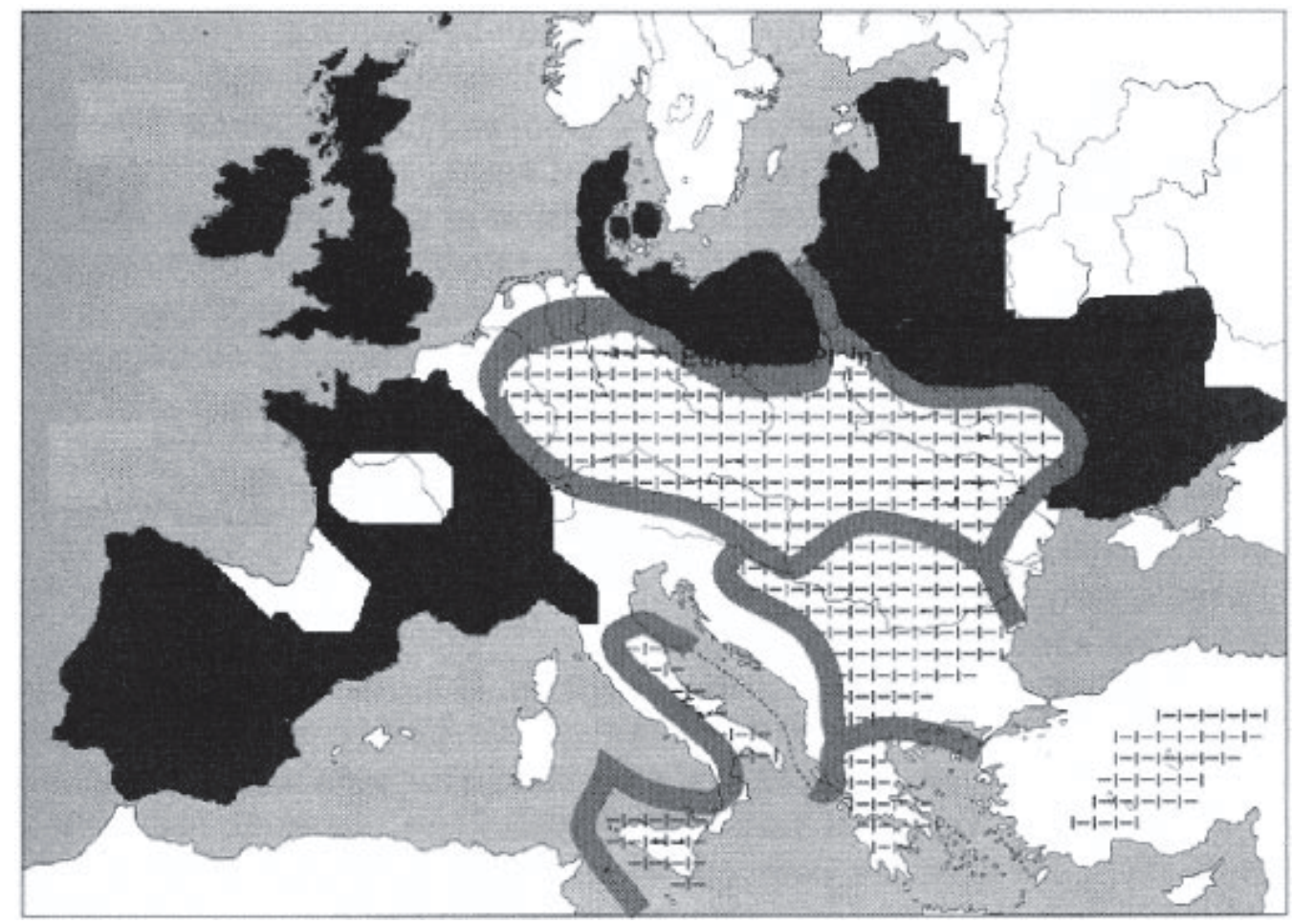

Figure 1. Possible zones of demic diffusion and of adoption-diffusing during the Neolithic transition. Stippled zones indicate major frontiers, cross-hatching indicates areas where demic diffusion is thought to have been significant, and black shading indicates areas where adoption-diffusion is thought to have been the mechanism of transition. Unshaded areas have not yet been classified in this particular binary scheme. After Zvelebil \& Lillie, 2000: 63

\section{Methods}

The basis of our re-evaluation was the collection of a spatial database of radiocarbon dates for the later Mesolithic and early Neolithic of Europe, roughly 9000-5000 BP; this time frame covers the range from the later Mesolithic in southeast Europe to the earlier Neolithic in northern and northwest Europe. In addition information was collected about the contexts of the dates, the material dated and economic and cultural associations. Europe was defined as the area to the west of a line from the Black Sea to the eastern Baltic. 
It became clear in the course of the project that, despite the large sums of money which have been spent over the years on radiocarbon dating in Europe, the state of public availability of the dates, their context and associations and details which enable users to judge the reliability of dates is in general very poor. Thus, no claim is made that the database is in any sense complete. To achieve this would take a major collaborative European exercise over many years. A total of just over 2600 samples were eventually included in the database. This involved the exclusion of dates about which there were grounds for suspicion in terms of their reliability and associations. Much of the information for this was obtained from Gob (1990) but similar judgements were also made about other dates on the basis of internal evidence from their sources. Again, we would not claim to avoided errors of both inclusion and exclusion, for the reasons just mentioned, but since our interest is in identifying continent-wide patterns on the basis of large numbers of observations we do not believe that these affect our conclusions.

The database consists of four main tables apart from the references. They are described in Table 1, where shortcomings are also noted. The database is available through the UK Archaeology Data Service (http://www.ads.ahds.ac.uk).

\section{Analytical approaches}

Two sets of analyses were carried out using the database: a set of spatial analyses for the whole of Europe examining the extent to which the subsequent accumulation of dates supported or modified the patterns suggested by Clark (1965) and by Ammerman and Cavalli-Sforza $(1971,1984)$; and a further set of analyses by country to look at the relation between Mesolithic and Neolithic dates and the light this might throw on demographic models for the transition.

\section{Spatial analyses}

A set of 508 Neolithic sites and 207 Mesolithic sites was used in these analyses. The classification of dates as Mesolithic or Neolithic was on the basis of conventional cultural assignment. While in principle it is important to distinguish the spatial and chronological distribution of different elements of the Neolithic 'package', in practice it is not currently possible to do this given the quality of the available information. Nevertheless, we feel that accepting the conventional cultural distinctions gives us a valid initial view of the situation. A single date was taken for all distinct sites in each of the two categories for which latitude./ longitude. co-ordinates were available; at sites where there are multiple radiocarbon dates, only the earliest Neolithic date and/or the most recent Mesolithic date were used. For the initial analysis, the visualization techniques were similar to those used by Clark (1965) and Ammerman \& Cavalli-Sforza (1971, 1984).

Following Clark (1965), the 508 Neolithic dates were grouped into temporal categories at 1200-year intervals (in uncalibrated years BC). Following Ammerman \& Cavalli-Sforza $(1971,1984)$, a major axis regression analysis was undertaken of the date of early farming sites compared with their distance from a nominal origin at Jericho. Neolithic dates (in uncalibrated years BP) were imported into a Grass GIS package, and contour lines fitted to the data at 500 year intervals. The procedure was first used to produce an isochron map using Ammerman and Cavalli-Sforza's data (Figure 2) and then, using the new data-base, for Mesolithic sites (Figure 6) and Neolithic sites (Figure 7). 
Table 1. Structure of the radiocarbon database. The database is constructed in Microsoft Access. The sources used include publications, radiocarbon lab databases and other relevant data sets from universities or archaeological bodies. Full details are given with the database. Site co-ordinates in latitude and longitude were obtained from the sources which provided the dates. British and Irish sites were reported in the relevant OS grids, and therefore had to be converted to WGS84 in order to be incorporated in the database. For the calibration of the dates OxCal 3 beta. 2 was used, which provides the 93 calibration curve.

\begin{tabular}{lll}
\hline Table Name & Table Fields & Comment \\
\hline Sample & $\begin{array}{l}\text { sample ID, date BP, error, } \\
\text { calibrated dates BC earliest and } \\
\text { latest } 1 \text { and } 2 \text { sigma, kind of lab } \\
\text { (AMS or conventional), } \\
\text { treatment, delta }{ }^{13} \mathrm{C} \text { correction, } \\
\text { material, comments, date of } \\
\text { process, source, lab code, } \\
\text { submitters }\end{array}$ & $\begin{array}{l}\text { Information not complete in some fields as lab } \\
\text { information rarely mentioned in publications or } \\
\text { databases }\end{array}$ \\
$\begin{array}{l}\text { sample ID, site name, site ID, } \\
\text { area, country, cultural ID, site } \\
\text { type, latitude, longitude, } \\
\text { comments, period, references, } \\
\text { association }\end{array}$ & $\begin{array}{l}\text { The 'site type' field could not be completed in } \\
\text { many cases as the relevant information was not } \\
\text { available. Latitude and longitude could not be } \\
\text { obtained for about 250 sites. The 'period' field } \\
\text { states the temporal characterisation (in } \\
\text { archaeological conventional terms) of the relevant } \\
\text { site by the archaeologist in charge. The 'references' } \\
\text { field has information that was provided by the } \\
\text { sources used. Gob (1990) provided comments on } \\
\text { the quality of the association between sample and } \\
\text { purported context for those dates he included and } \\
\text { such information was obtained from other sources } \\
\text { wherever possible. }\end{array}$ \\
$\begin{array}{ll}\text { Site phase } \\
\text { Context }\end{array}$ & $\begin{array}{l}\text { Only rarely could relevant information be added } \\
\text { in the table, as the site reports are generally the } \\
\text { only source for this kind of information. }\end{array}$ \\
$\begin{array}{l}\text { Sample ID, site phase, absence } \\
\text { or presence of pottery, } \\
\text { domesticated animals and plants } \\
\text { and human remains. }\end{array}$ & $\begin{array}{l}\text { Again site reports are necessary for the type of } \\
\text { context, as well as for the completion of the 'site } \\
\text { phase' and 'context' fields. The 'Site Phase' and } \\
\text { 'Context' tables should be used together as there is } \\
\text { no consistency in the way the two terms have been } \\
\text { used in the data sources }\end{array}$ \\
\hline
\end{tabular}

We also undertook other map visualizations and statistical analyses (Russell \& Steele in press, see also Glass et al. 1999). First, we experimented with geographically-weighted regression (Fotheringham, Brunsdon \& Charlton 2000, 2001), a technique which allows us to detect local variation in trends in large-scale spatial datasets, by weighting each control datum in a regression analysis inversely to its distance from a specified point location.

A second new method of analysis uses ranges of calibrated dates rather than point values. Ammerman \& Cavalli-Sforza's and Clark's methodologies used uncalibrated dates and treated 


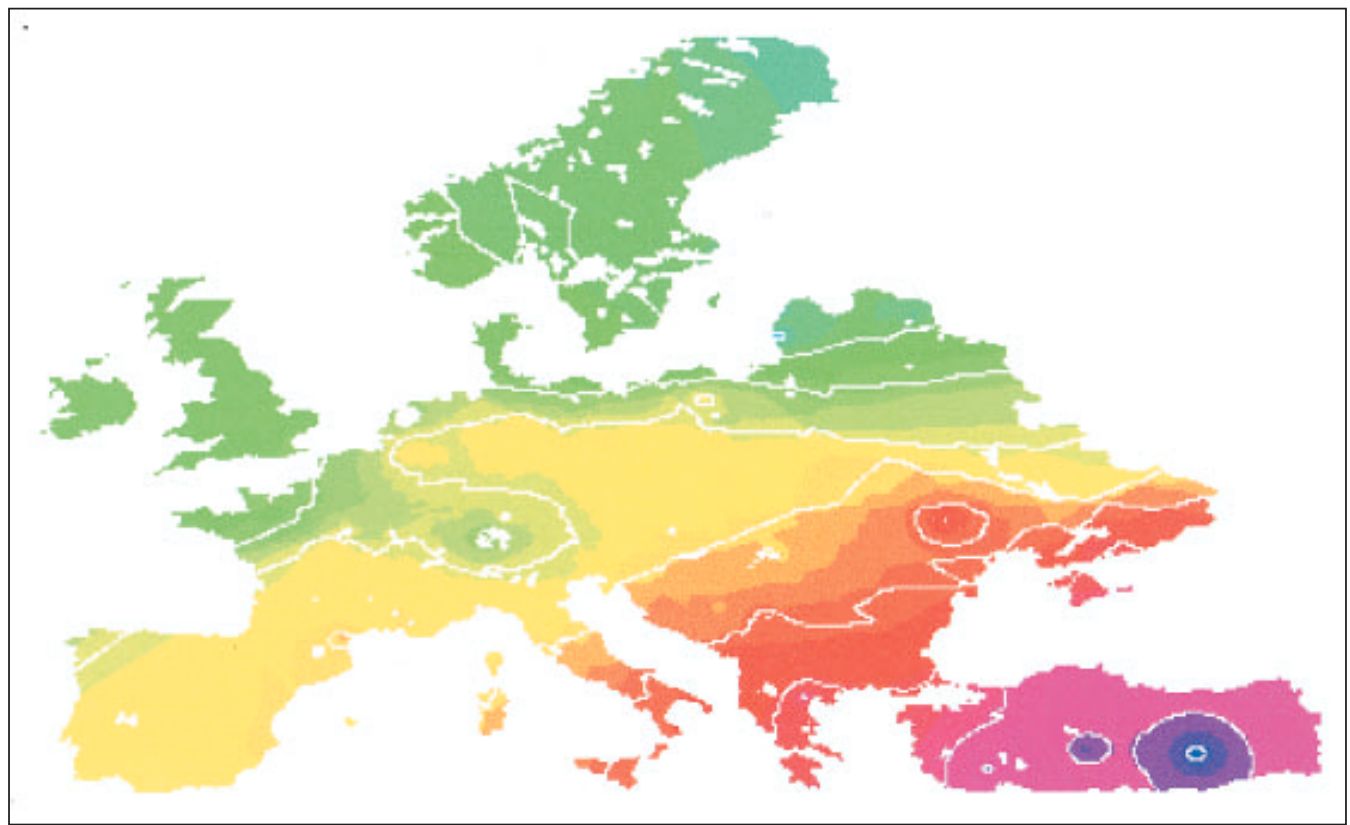

Figure 2. Contour map produced using Ammerman \& Cavalli-Sforza's (1984) site list and the surface interpolation and contour fitting using the GIS software, GRASS.

the date's modal value as a point value. The irregular shape of many of the calibrated probability distributions of radiocarbon dates makes statistical treatment that requires point values problematic (Figure 3). Most commonly this is overcome by treating the modal value of the radiocarbon probability distribution as a point value and using weighted regression to minimize the influence of dates with a large associated error (e.g. Glass et al. 1999). We wanted to assess how problematic the use of the modal value might be, particularly in instances when the calibrated radiocarbon distribution deviates from a normal distribution (for example, Figure 3). To do this dates were calibrated in OxCal3 (Ramsey 1999). The area under the calibration curve was used to calculate the probability that a site was occupied within a given interval of the calibrated date range. The probability that a site was occupied at successive 100 -year intervals is reflected by the rise and fall in the area of the circle that marks a site's location. Both the late Mesolithic and the early Neolithic dates were used in the analysis.

In the second set of analyses dates were categorised by country, to give a broad regional breakdown, and the summed calibrated probabilities of the dates were obtained, with Mesolithic and Neolithic dates distinguished from one another. The rationale for this is the assumption that fluctuations through time in the summed probabilities should give a general indication of fluctuations in settlement intensity. The fact that the absolute numbers of Mesolithic dates are in general much lower than for the Neolithic may or may not give an indication of the relative intensity of settlement in the two periods given the different types of archeological evidence which generally characterise them. However, even if this is not the case, the fluctuations within each period within a given broad region should be interpretable in this way, so long as the number of dated sites is not too small. 


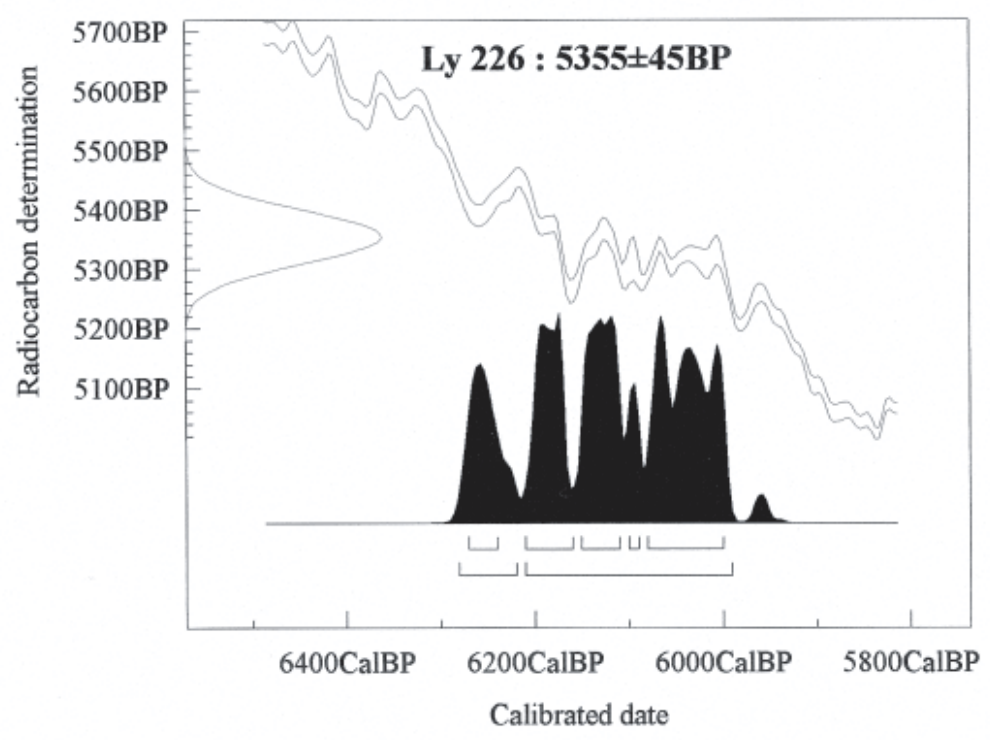

Figure 3. The calibrated probability distribution of a radiocarbon determination from the Neolithic site of Camp del Ginebre, France to show the irregular shape of the calibrated date's probability distribution.

\section{Results}

\section{Spatial analyses}

Clark's map of the changing distribution of early farming sites is closely mirrored when the expanded database of Neolithic sites is analysed (Figure 4). Sites are older close to the origin in the Near East and they become increasingly younger with movement in a north-west direction from this origin. Ammerman \& Cavalli-Sforza's (1971, 1984) major regression analysis of rates of spread from an assumed origin at Jericho was repeated with the new database (using 510 radiocarbon determinations) (Figure 5), yielding the major axis equation: $\mathrm{y}_{\text {date }}=(-0.77 \pm 0.03) \mathrm{x}_{\text {distance }}+(8240 \pm 110)$.

This suggests that the overall rate of spread is $-1.3 \mathrm{~km} /$ year and that the mean notional departure time from Jericho was $\sim 8240 \pm 110 \mathrm{yrs} \mathrm{BP}$ (uncal.). In this case, linear regression of the two variables produces a correlation coefficient, $r=0.73$. In other words, with the larger data set now available the mean rate of spread is similar to that observed by Ammerman \& Cavalli-Sforza, although the dispersion around that rate is somewhat greater.

It is important to note that calibrating the radiocarbon values derived from in this major axis model would give us a mean origination time in Jericho of about $10400 \mathrm{cal}$ BP for European Neolithic populations. If we approximate a confidence range for this date by taking estimates from linear regression models for dates on distance and for distance on dates (cf. Draper 1992), we derive a range for the mean Near Eastern origination time of 9200 $12400 \mathrm{cal} \mathrm{BP}$. Such estimates fit quite well with observed dates for the end of the Natufian (c. 10200 BP, Belfer-Cohen 1991, which becomes c. 12000 cal BP after calibration). This is interesting when we consider that current debate about European genetic origins contrasts a possible major dispersal at 11-14 $000 \mathrm{cal} \mathrm{BP} \mathrm{(variously} \mathrm{described} \mathrm{as} \mathrm{'Mesolithic'} \mathrm{by} \mathrm{Sykes,}$ 1999 and as 'Late Upper Palaeolithic' by Richards et al., 2000), with one at 8500 cal BP 
Marina Gkiasta, Thembi Russell, Stephen Shennan and James Steele

(a)

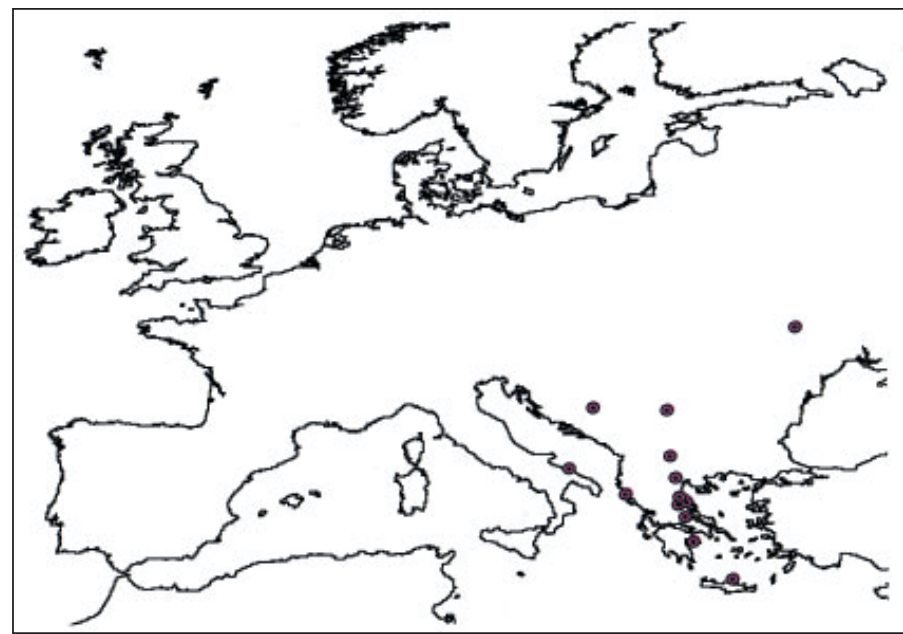

(b)

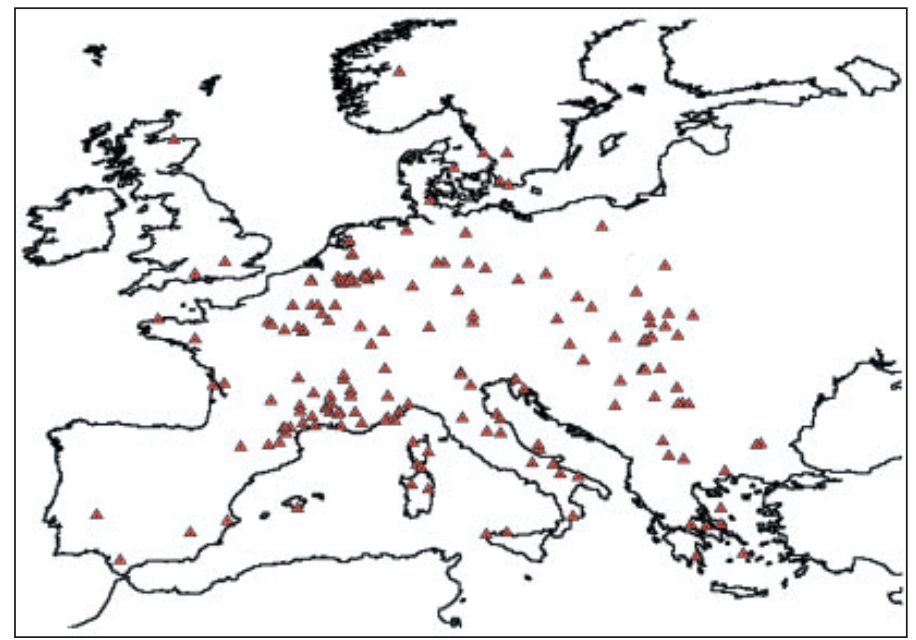

(c)

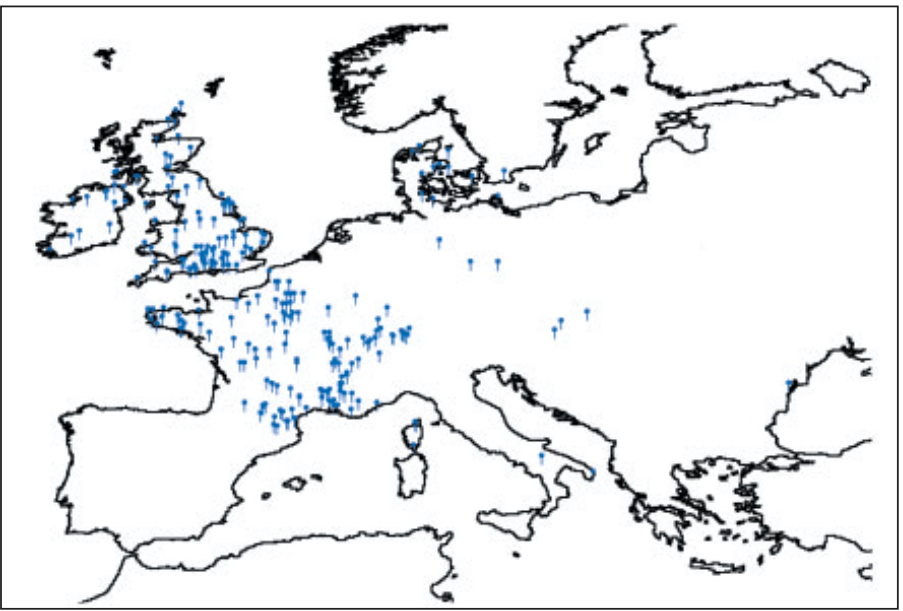


(d)

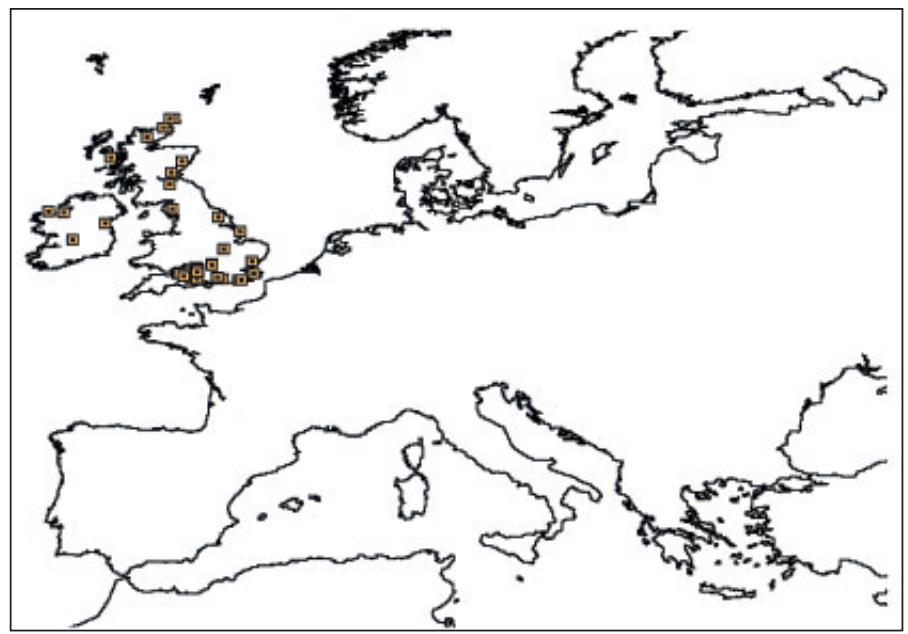

(e)

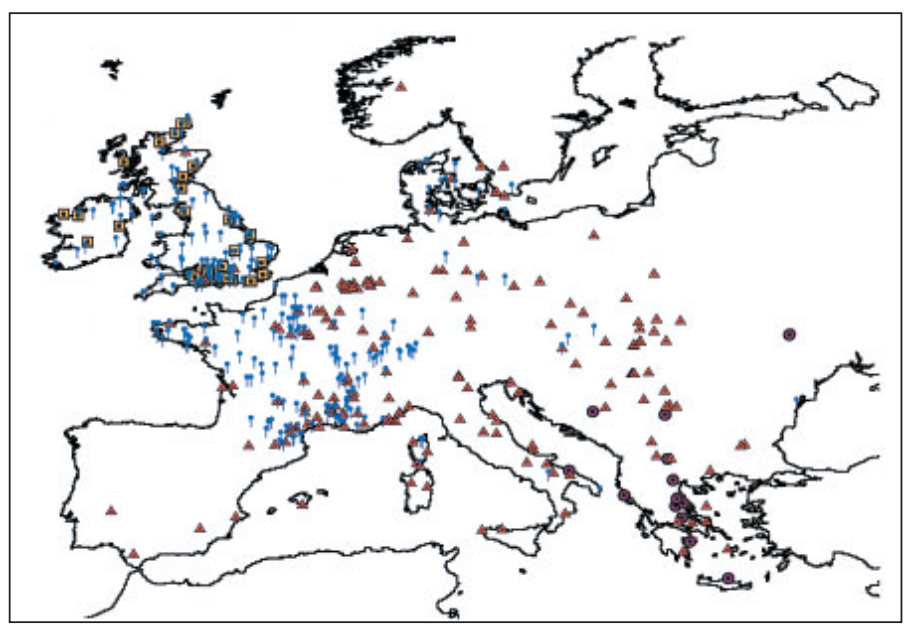

Figure 4. (a) Neolithic sites, radiocarbon determinations greater than 5200 BC. (b) Neolithic sites, radiocarbon determinations for the period 4000 to $5200 \mathrm{BC}$. (c) Neolithic sites, radiocarbon determinations within the time period 2800 to 4000 BC. (d) Neolithic sites, radiocarbon determinations that are more recent than 2800 BC. (e) All the sites grouped within the 1200-year time interval (after Clarke 1965).

Maps to show the spatial distribution of the new database were produced in the GIS package, Arcview.

(described as 'Neolithic' by Sykes, 1999). In other words, one effect of calibration is that the mtDNA signatures of these two events appear less well-resolved than some geneticists suggest. Some of the mtDNA variation currently attributed to the late glacial recolonization of Europe may in fact derive from Neolithic demic diffusion!

The isochron maps compiled to show the distribution of the last foraging and first farming sites in Europe (Figures 6 and 7) also share parallels with Ammerman \& Cavalli-Sforza's isochron maps. The delay in the expansion into the Alpine area shows up clearly in the newly compiled isochron map of the early Neolithic (Figure 7). The overall expansion northwestwards from a near eastern origin is maintained, although the isochrons are less regularly spaced suggesting a much greater variance in the rate of spread of early farmers into the 


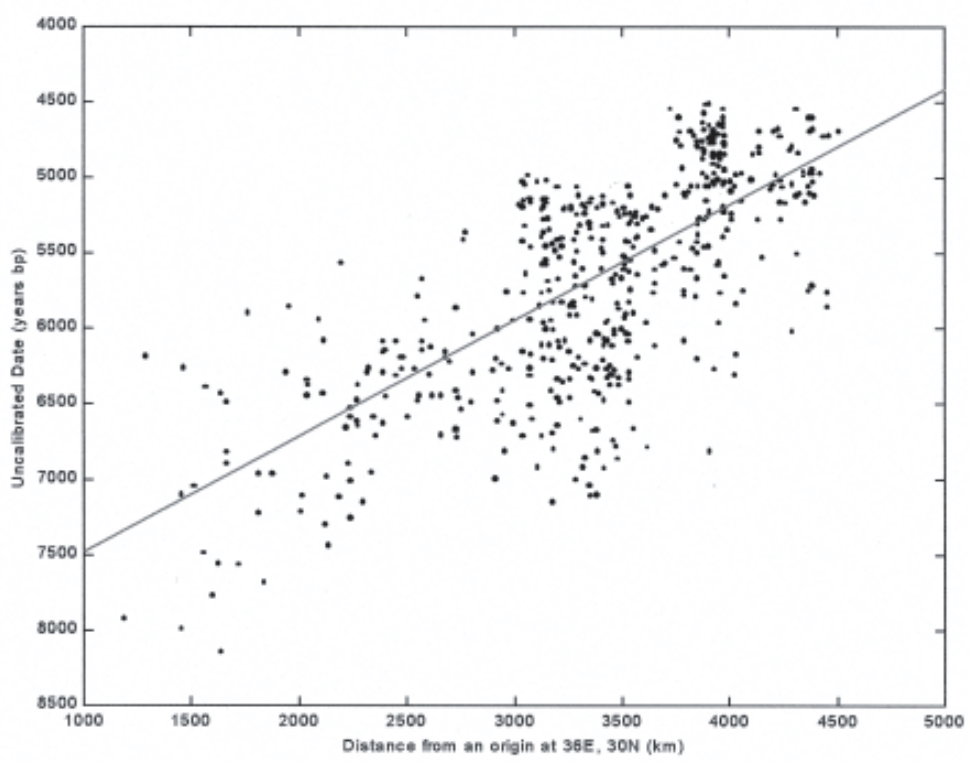

Figure 5. Regression analysis of geodesic distance from an assumed origin south of Jericho (kms, $y$-axis) with the site age (years BP, $x$-axis). 510 radiocarbon determinations (for early Neolithic sites) are used in the analysis.

different areas of Europe. But we must recognize the methodological limitations of this technique. Interpolation error will be large in regions with sparse or no sites to use as control points, and the interpolation has been continuous across sea as well as land (although the sea has subsequently been masked off). This technique therefore risks giving a misleadingly coherent impression of the spatial structure of any such dataset.

In Figure 8 we have plotted results of a locally-weighted linear trend analysis for the ages of early Neolithic sites, for each of a regular grid of points. It is a convention that vector field diagrams should plot values on a regular grid in this way. We have used projected co-ordinates, and we have only used the earliest sites in each $60 \mathrm{~km}-$ by- $60 \mathrm{~km}$ cell of a sampling grid. The orientations of the arrows show the direction in which sites get younger. The lengths of the arrows scale to the rate of spread. The colours of the arrows indicate the strength of the locally-weighted linear trend (where red is a well-fitting model, and blue is a poorly-fitting model). What this technique shows us is that we can only pick up significant regional trends in regions where our dataset is full, rather than sparse. This technique therefore combines the best elements of the previous two (as used by Ammerman and Cavalli-Sforza), but avoids their weaknesses. We can observe local variation in rate and direction of diffusion, and its statistical strength. We do not need to assume any single origin, and we can see the regions where the model fits well and the regions where it fits badly.

However, this too is an oversimplification. When the whole of the calibrated date distribution is used to show spread, rather than the modal value of the uncalibrated date, the pattern of spread is far less obvious. The value in this approach is twofold: it emphasises the probabilistic nature of radiocarbon dates, and it enables us to see the extent of co-occurrence of Mesolithic and Neolithic sites within a region. Neither of these aspects of the chronology of the transition can be easily visualised using regression techniques or spatial interpolation methods. 
Neolithic transition in Europe: the radiocarbon record revisited

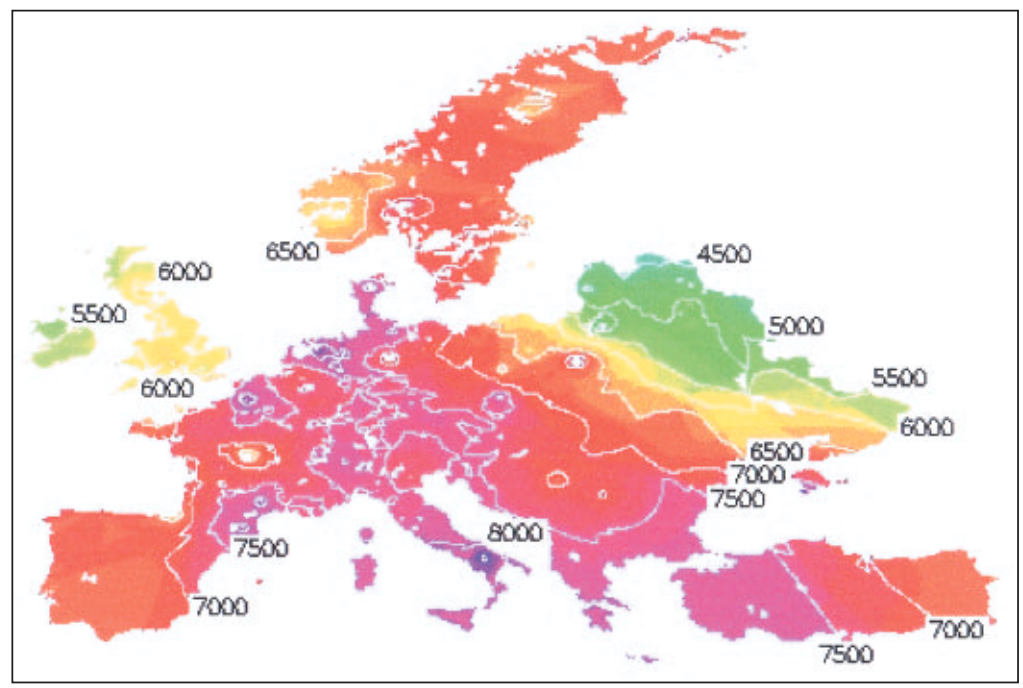

Figure 6. Isochron map of the most recent Mesolithic sites in Europe. 207 Mesolithic dates are used. Isochrons are at 500radiocarbon-year intervals. Radiocarbon ages are uncalibrated years $B P$.

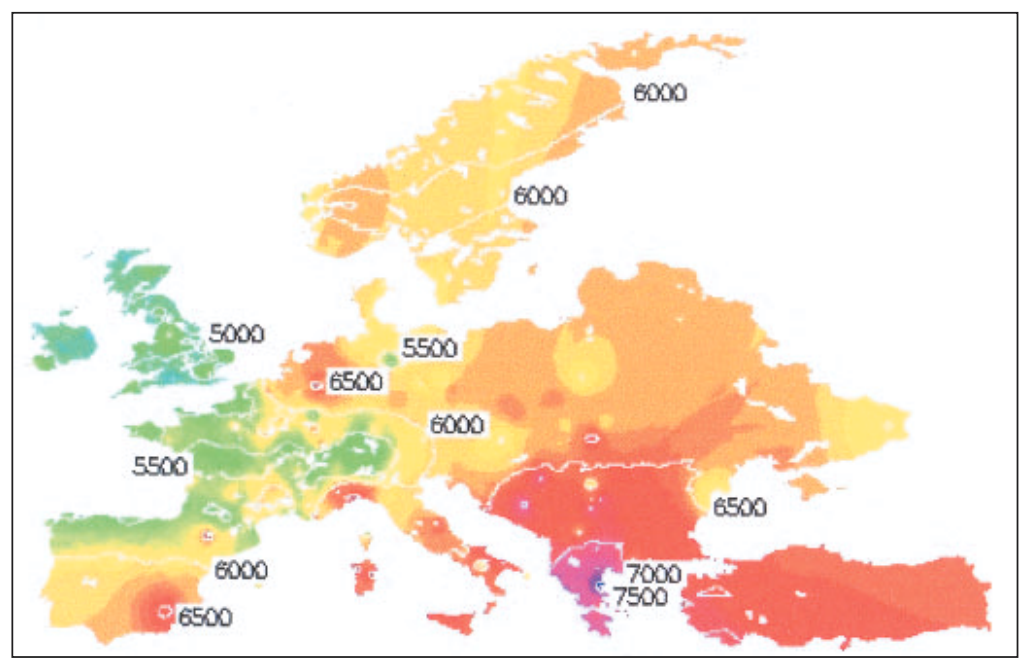

Figure 7. Isochron map for the distribution of early Neolithic sites using 508 radiocarbon dates. Isochrons are created at 500-radiocarbon-year intervals. Dates are uncalibrated years BP. 


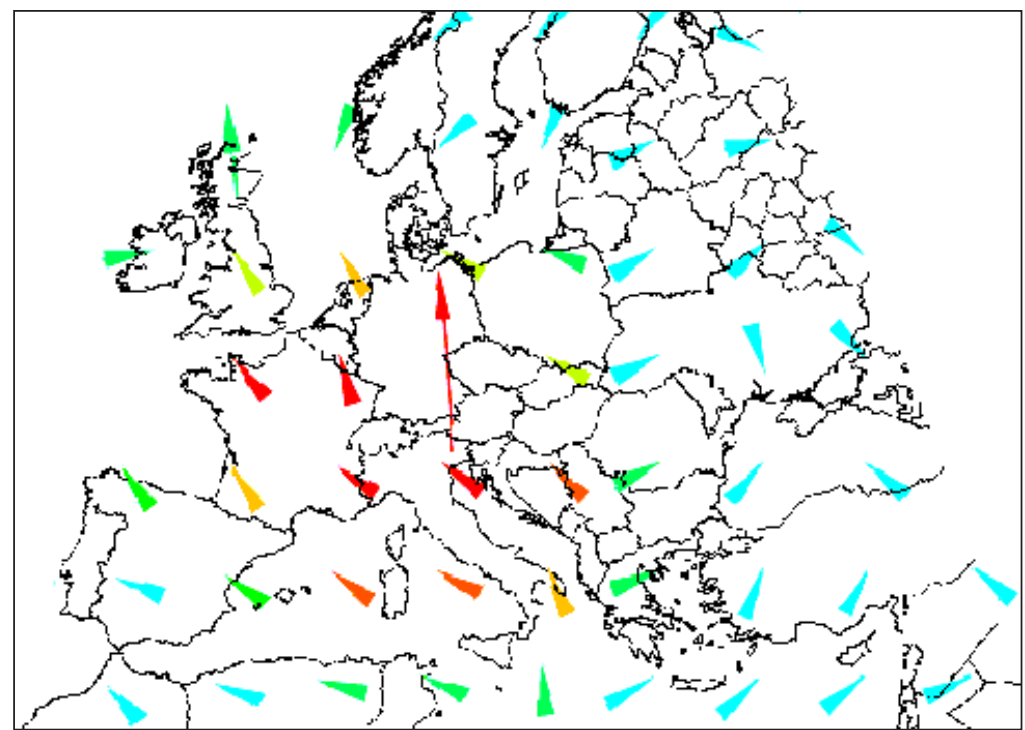

Figure 8. Results of a locally-weighted linear trend analysis for the ages of early Neolithic sites, for each of a regular grid of points. The orientations of the arrows show the direction in which sites get younger. The lengths of the arrows scale approximately to the rate of spread. The colours of the arrows indicate the strength of the locally-weighted linear trend (where red is a wellfitting model, and blue is a poorly-fitting model). Bandwidth = 400. Compare with the data distribution plotted in Figure 4.

\section{Regional analyses}

The results of this procedure for countries with a reasonable number of dates are shown in Figures 9 and 10. It should be noted that the probability distributions of the Mesolithic and Neolithic dates are separately normalised to the same height and do not reflect the different numbers of samples used. It is also important to emphasise that the end cut off date of the Neolithic dates is relatively arbitrary. Within any given region, dates were included that were associated with cultures regarded as characteristic of the local earlier Neolithic. Subdividing the dates by country is a very rough and ready way of obtaining a regionalisation and summed date probabilities a very coarse measure of occupation, but perhaps the most striking feature of the country-by-country patterns shown in Figures 9 and 10 is how very varied they are, and this variation has potential significance for the relevance of the models of 'neolithisation' in the different regions.

We shall look separately at regions which Zvelebil \& Lillie (2000, cf Figure 1) characterise as experiencing significant demic diffusion (Figure 9), and regions which they characterise as experiencing predominantly trait adoption-diffusion (Figure 10). Overall, we have the impression from these probability plots that in regions of predicted demic diffusion the appearance of an early Neolithic population was relatively abrupt: that is, there is no long "fat negative tail" to these summed distributions. Secondly, in regions of predicted demic diffusion, Mesolithic dates tend either to disappear well ahead of the establishment of early Neolithic occupation, or to continue at a fairly constant rate well after it. By contrast, in areas of predicted trait adoption-diffusion we do see such long fat negative tails to the early Neolithic distributions, implying a more gradual rate of increase in Neolithic settlement density. In such regions, the Mesolithic radiocarbon record tends to tail off gradually with significant overlap with that of the early Neolithic. We can now make some more specific, but still impressionistic suggestions about these pooled radiocarbon records. 


\section{Neolithic transition in Europe: the radiocarbon record revisited}
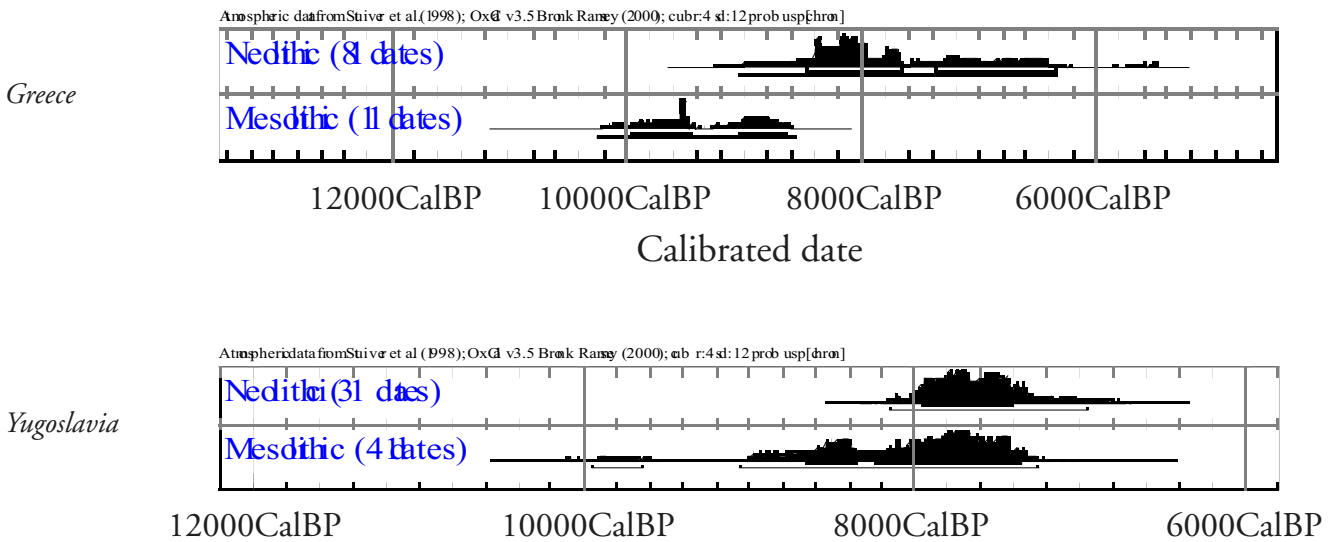

Calibrated date
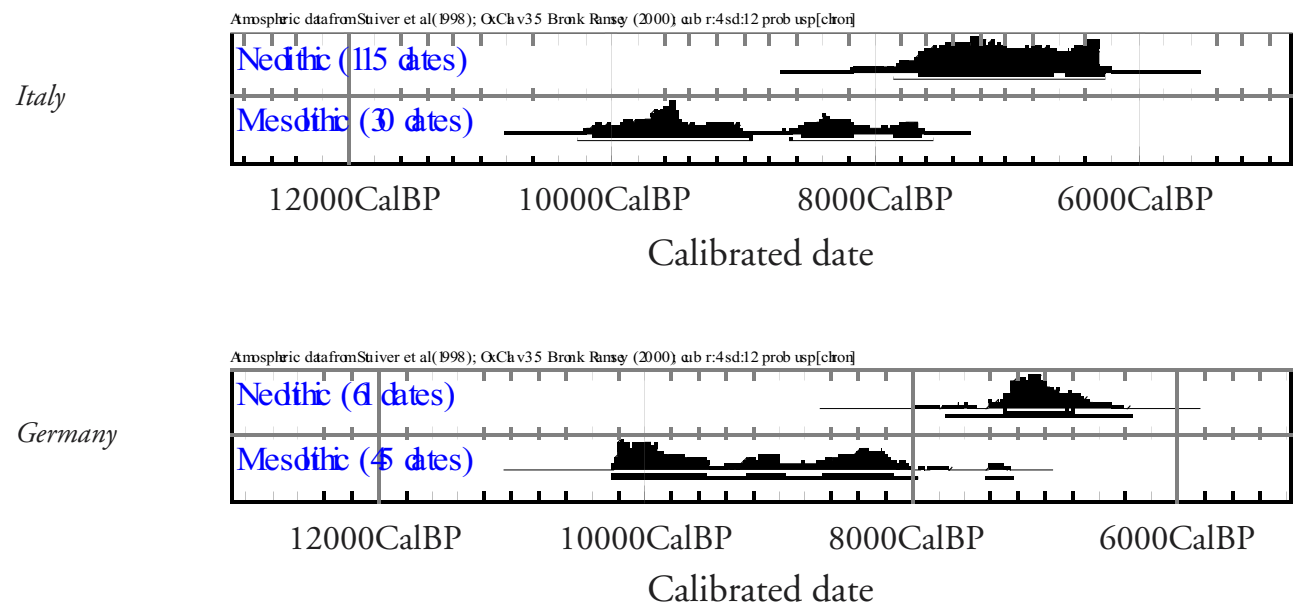

Belgium

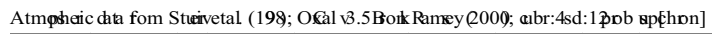

\begin{tabular}{|c|c|c|c|}
\hline Nedithic (3Qlates) & & & - \\
\hline Mesolithic (1 Glates) & $=$ & 111 & \\
\hline 12000CalBP & 10000CalBP & 8000CalBP & 6000CalBP \\
\hline
\end{tabular}

Figure 9. Summed probabilities for late Mesolithic and early Neolithic dates in countries where demic diffusion is predicted to have been a significant mechanism. 
France

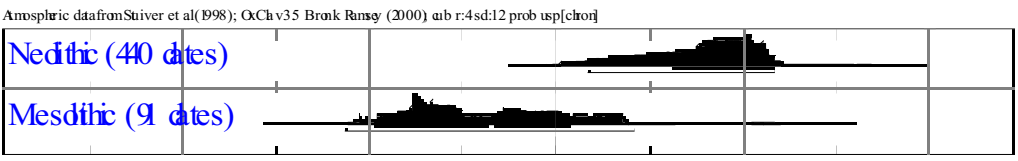

12000CalBP 10000CalBP 8000CalBP 6000CalBP 4000CalBP

Calibrated date

France $>47 N$

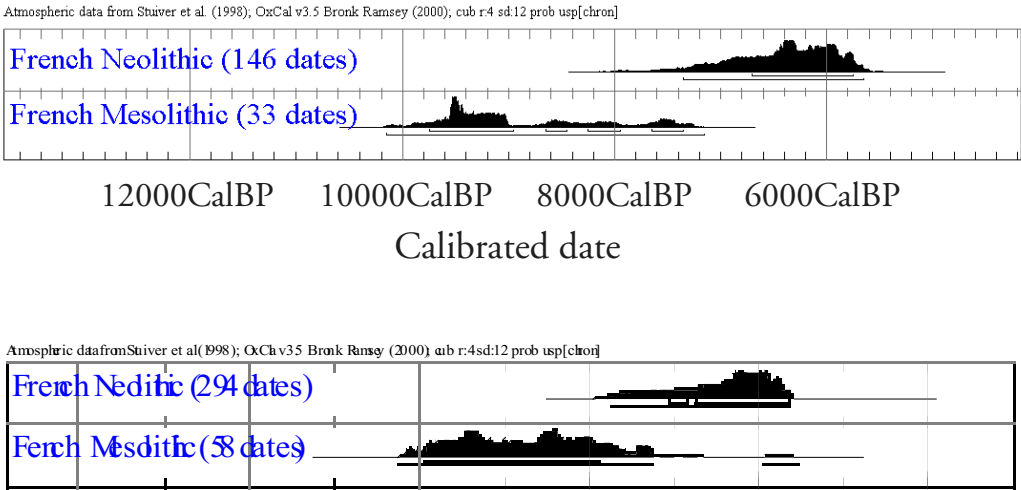

France $<47 N$

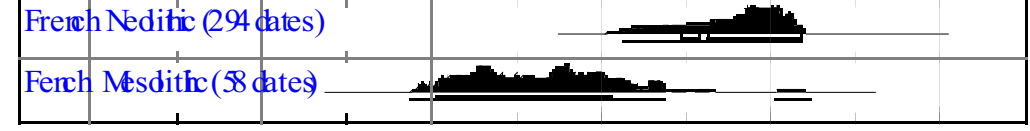

14000CalBP 12000CalBP 10000CalBP 8000CalBP 6000CalBP 4000CalBP

Calibrated date

Great Britain

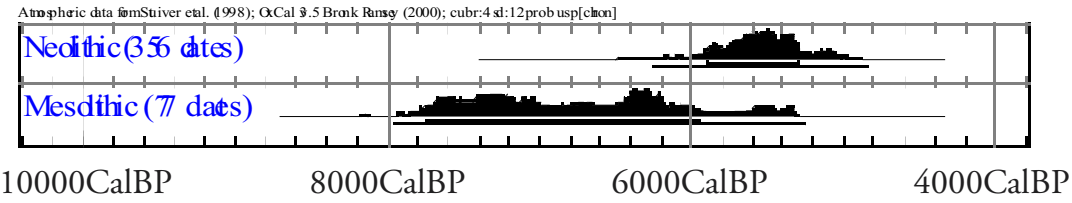

Calibrated date

Ireland

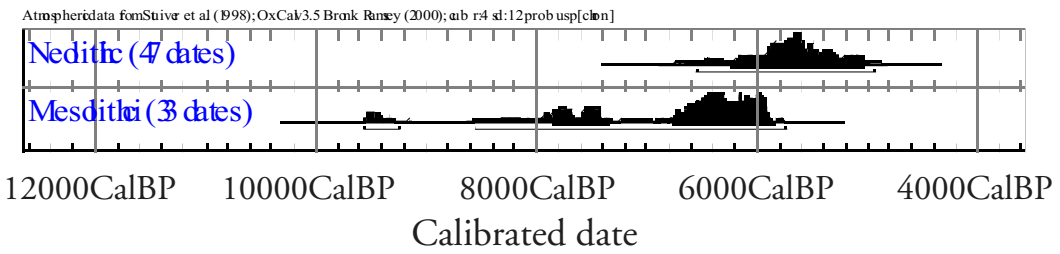

Figure 10. Summed probabilities for late Mesolithic and early Neolithic dates in countries where trait adoption-diffusion is predicted to have been the dominant mechanism. 


\section{Regions predicted to have experienced demic diffusion}

The pattern for Greece does not contradict the view that we are dealing with the expansion of new populations from Anatolia rather than an indigenous Neolithic development. However, the number of Mesolithic dates is still small and it remains unclear how much the current state of affairs reflects lack of work rather than lack of settlement.

In the former Yugoslavia the Mesolithic dates come from a very small number of sites, dominated by Lepenski Vir, indicating a need for caution. Nonetheless, what emerges is a Neolithic represented by the Star evo culture which appears very suddenly at around 8000 cal.BP, most probably as a result of populations expanding from Greece, and a Mesolithic which carries on in such locations as the Iron Gates gorges or the mountains of Montenegro, overlapping and interacting with the newly arrived Neolithic colonists.

Italy has a rather firmer foundation and at first sight looks more ambivalent in terms of its possible implications for 'neolithisation' processes since there is a later Mesolithic concentration of dates immediately prior to and overlapping with the earliest Neolithic ones. However, an examination of the geographical location of the sites concerned reveals that all the late Mesolithic sites are in northern Italy while virtually all the earliest Neolithic dates come from the south, suggesting that in this region at least the earliest Neolithic is likely to represent colonisation.

In Germany there is a marked decline Mesolithic occupation before 8000 cal.BP and the body of the Neolithic distribution begins very sharply at around 7400 cal.BP, associated with the appearance of the Linearbandkeramik (LBK). This would seem to suggest a decline in Mesolithic occupation after 8000 cal.BP and hardly fits in with the suggestion that the German LBK represents an indigenous adoption of Neolithic culture and economy. On the contrary, it seems to confirm the idea of the LBK as an expanding, colonising population moving into an area which was relatively thinly occupied. However, the probable presence of Mesolithic groups with distinctive La Hoguette pottery in the west of the area should be noted (see e.g. Jochim 2000, Figure 7.5). The recent work of Price et al. (2001; see also Bentley et al. 2002), involving strontium isotope analysis of LBK skeletons, suggests both population immigration and some degree of mixing with neighbouring groups, possibly foragers.

In the case of Belgium a continuous low level of Mesolithic occupation is suggested, continuing in parallel with the early Neolithic, but examination of the coordinates of these later Mesolithic sites indicates that they are located significantly further west than their early Neolithic contemporaries. The Neolithic begins quite abruptly at 5400 cal. BC with the earliest Bandkeramik settlements.

\section{Regions predicted to have experienced trait adoption-diffusion}

The pattern for France once again shows a series of Mesolithic fluctuations but its most striking feature is the very gradual increase in the number of Neolithic dates through time. A low Mesolithic level leading up to 7500 cal. BP gives way to a gradually rising intensity of Neolithic occupation. Two-thirds of the very earliest Neolithic dates, ie. those where the beginning of the $1 \sigma$ calibrated range goes back before $7000 \mathrm{cal}$. BP, are from the southern half of France and associated with Cardial and related cultures, while the remaining third are 
northern French LBK-related dates. There would appear to be strong evidence here for the early indigenous adoption of Neolithic attributes by Mesolithic populations in France, at least in its southern half. In this respect the radiocarbon evidence supports the inferences made from the presence of sherds of west European La Hoguette pottery in early LBK sites (see again, Jochim 2000). The number of French dates is sufficiently large to examine this geographical issue more closely, by dividing the French dates into a southern and a northern set at 47 degrees latitude to see if there is any difference in the pattern on 'neolithisation' between that in the south derived from the Mediterranean Impressed Ware route and that in the north, where there was strong LBK influence (Figure 10). Perhaps surprisingly, the pattern seems to be the same in both northern and southern France, corresponding to the overall pattern noted above of gradually rising Neolithic occupation, but with a 400 year delay in the northern half; in southern France the 95\% confidence interval for the Neolithic dates begins at c. $7800 \mathrm{cal}$. BP, while in northern France it is c.7400 cal. BP. However, the northern French pattern does not suggest a sudden LBK impact, such as we see elsewhere.

The picture for Britain is more ambivalent in that there is a decline in the summed Mesolithic probabilities prior to the rise of the Neolithic but in the light of the other patterns, it seems at present more convincing to see it as pointing towards indigenous adoption rather than than colonisation. This seems even more likely to be the case for Ireland, where the main Mesolithic peak is immediately prior to the beginning of the Neolithic, followed apparently by a very sudden transition. However, as Woodman (2000) makes clear, the picture remains very unclear.

\section{Concluding remarks}

Discussion of the spread of agriculture in Europe has been polarised in recent years. Proponents of demic diffusion have become increasingly embattled in the face both of archaeological arguments for regional variation in mechanism, and of genetic evidence favouring a combination of demic diffusion and adoption-diffusion in a population which largely retained its local, late Palaeolithic genetic composition, although recently they have been fighting back. Our initial analysis of the new radiocarbon database confirms the robustness of the spatial patterns described by Clark and by Ammerman \& Cavalli-Sforza. However, the existence of a clear correlation between date of earliest occurrence and distance from an assumed source is quite as compatible with a wave of advance of a cultural trait through a pre-existing population, as it is with a wave of population replacement. The gradients in gene frequencies plotted in synthetic gene maps can also be explained by multiple mechanisms, of which demic expansion is only one.

We conjecture that regional differences in the importance of demic and of adoption diffusion may reflect both underlying differences in the relative fertility and population density of local foraging and farming groups, and underlying differences in the readiness of foragers to convert to farming. As a first exploration of the demographic picture, we have plotted summed radiocarbon distributions by region, taking these as very approximate measures of occupancy by foraging and farming communities. We have proposed that in areas where demic diffusion is predicted to have occurred, a more abrupt transition may be visible. However, the underlying causes of such abruptness (if it is indeed a genuine pattern) remain to be investigated. The 
environmental factors differentiating regions of probable demic diffusion from those of probable adoption-diffusion also need to be examined in terms of their implications for forager and farmer demography. Our intention here is to stimulate further work on the large-scale patterns and processes, not to inhibit it by reinforcing that polarisation of debate which is tending to cause stagnation.

\section{Acknowledgements}

We wish to thank the UK Arts and Humanities Research Board for funding the database collection element of this work, which was carried out by Marina Gkiasta. Thembi Russell carried out the spatial analysis, and we gratefully acknowledge her support by a Southampton University Studentship in High Performance Computing. John Robb and two anonymous referees have kindly commented on earlier versions, and we have attempted to incorporate their very helpful suggestions.

The database collection was funded by a grant from the UK Arts and Humanities Research Board to Shennan and Steele, for the employment of Gkiasta.

\section{References}

Ammerman, A.J. \& L. L. Cavalli-Sforza. 1971 Measuring the rate of spread of early farming in Europe. Man n.s. 6: 674-688.

Ammerman, A.J. \& L. L. Cavalli-Sforza. 1984. The Neolithic Transition and the Genetics of Populations in Europe. Princeton: Princeton University Press.

Aoki, K., M. Shida \& N. Shigesada. 1996. Travelling wave solutions for the spread of farmers into a region occupied by hunter-gatherers. Theoretical Population Biology 50:1-17.

ARIAS, P. 1999. The origins of the Neolithic along the Atlantic coast of continental Europe: A survey. Journal of World Prehistory 13:403-464.

Barbujani, G. \& G. Bertorelle. 2001. Genetics and the population history of Europe. Proceedings of the National Academy of Sciences of the USA 98: 22-25.

Barbujani, G., R.R. SoKal \& N.L. Oden. 1995. IndoEuropean Origins - a Computer-Simulation Test of 5 Hypotheses.-American Journal of Physical Anthropology 96:109-132.

Belfer-Cohen, A. 1991. The Natufian in the Levant. Annual Review of Anthropology 20: 167-186.

Bentley, A., L. Chikhi \& T.D. Price. 2003. Comparing broad scale genetic and local scale isotopic evidence for the spread of agriculture into Europe. Antiquity 77:

Bentley, R. A., T.D. Price, J. LÜNing, D. Gronenborn, J. Wahl \& P.D. Fullagar. 2002 Human migration in early Neolithic Europe. Current Anthropology 43(5), in press.

Bogucki P, \& R. Grygiel. 1993. The 1st Farmers of Central-Europe - a Survey Article. Journal of Field Archaeology 20:399-426.
Chikhi, L., R. Nichols, G. Barbujani \& M.A. BeAumont. 2002. Y genetic data support the Neolithic diffusion model. Proceedings of the National Academy of Sciences USA 99: 1100811013.

Clark, J.G.D. 1965. Radiocarbon dating and the expansion of farming culture from the Near East over Europe. Proceedings of the Prehistoric Society 31: $57-73$.

Draper, N.R. 1992. Straight line regression when both variables are subject to error. Technical Report No. 890, Dept of Statistics, University of Wisconsin, Madison, WI.

FIX, A.G. 1996. Gene frequency clines in Europe: Demic diffusion or natural selection? Journal of the Royal Anthropological Institute 2:625-643.

FIX, A.G. 1997. Gene frequency clines produced by kin-structured founder effects. Human Biology 69:663-673.

Fotheringham, A.S., C. Brunsdon \& M.E. Charlton. 2000. Quantitative Geography. London: Sage.

-2001 Geographically Weighted Regression. http:// www.ncl.ac.uk/geography/GWR

Glass, C., Steele \& D. Wheatley. 1999 Modelling spatial range expansion across a heterogeneous cost surface. In Procs. CAA 97, Birmingham. BAR Int Series 750: 67-72. Oxford: Archaeopress.

GoB, A. 1990. Chronologie du Mésolithique en Europe. Atlas des Dates ${ }^{14} \mathrm{C}$. Liège: C.I.P.L.

Gronenborn, D. 1999. A variation on a basic theme: The transition to farming in Southern Central Europe. Journal of World Prehistory 13:123-210.

Jochim, M. 2000. The origins of agriculture in southcentral Europe. In Price, TD (ed.) Europe's First Farmers, pp. 183-196. Cambridge: Cambridge University Press. 
Price, T.D., R.A. Bentley, J. Lüning, D. Gronenborn \& J. WAHL. 2001. Prehistoric human migration in the Linearbandkeramik of Central Europe. Antiquity 75: 593-603.

Ramsey, C.B. (1999) OxCal Program v.3.b2. http:// www.rlaha.ox.ac.uk/oxcal/oxcal.htm

Rendine, S., A. Piazza \& L.L. Cavalli-Sforza. 1986. Simulation and separation by principal components of multiple demic expansions in Europe. American Naturalist 128: 681-706.

Richards, M., H. Corte Real, P. Forster, V. Macaulay, H. Wilkinson Herbots, A. Demaine, S. Papiha, R. Hedges, H.J. Bandelt \& B. Sykes. 1996. Paleolithic and Neolithic lineages in the European mitochondrial gene pool. American Journal of Human Genetics 59:185-203.

Richards, M.B., V.A. Macaulay, H.J. Bandelt \& B.C. SYKES.1998 Phylogeography of mitochondrial DNA in western Europe. Annals of Human Genetics 62:241-260.

Richards, M., V. Macaulay, E. Hickey et al. 2000. Tracing European founder lineages in the near eastern mtDNA pool. American Journal of Human Genetics 67: 1251-1276.

Richards, M.P. \& R.E.M.Hedges. 1999 A Neolithic revolution? New evidence of diet on the British Neolithic. Antiquity 73:891-897.

Rosser, Z.H., T. Zerjal, M.E. Hurles et AL. 2000. Ychromosomal diversity in Europe is clinal and influenced primarily by geography, rather than by language. American Journal of Human Genetics 67: (6) $1526-1543$.

Russell, T. \& J. Steele. (in press) Visualising the Neolithic transition in Europe. Proceedings of the Fourth $C^{14}$ and Archaeology Conference, Oxford. Oxford: Oxbow Books
SEMINO, O. ET AL. 2000. The genetic legacy of palaeolithic Homo sapiens sapiens in Europe: a Y chromosome perspective. Science 290: 1155-1159.

Simoni, L., F. Calafell, D. Pettener, J. Bertranpetit \& G. Barbujani. 2000. Geographic patterns of mtDNA diversity in Europe. American Journal of Human Genetics 66:262-278.

Sokal, R.R., N.L. Oden \& B.A. Thomson. 1999. A problem with synthetic maps. Human Biology 71:1-13.

SYKES, B. 1999. The molecular genetics of European ancestry. Philosophical Transactions of the Royal Society of London Series B - Biological Sciences-354: 131-138.

WoOdman, P. 2000. Getting back to basics: transitions to farming in Ireland and Britain.. In Price, TD (ed.) Europe's First Farmers, pp. 219-259. Cambridge: Cambridge University Press.

Zvelebil, M. \& P. Dolukhanov. 1991. The Transition to Farming in Eastern and Northern Europe. Journal of World Prehistory 5:233-278.

ZvelebiL, M. 1996. The agricultural frontier and the transition to farming in the Circum-Baltic region. In Harris, DR (ed.) The Origins and Spread of Agriculture and Pastoralism in Eurasia, pp. 323345. London: UCL Press.

Zvelebil, M. \& M. Lillie. 2000. Transition to agriculture in eastern Europe. In Price, TD (ed.) Europe's First Farmers, pp. 57-92. Cambridge: Cambridge University Press. 